\title{
THE SPECTRUM OF CONGENITAL MYOPATHIES IN ROMANIA - A PATHOLOGICAL RETROSPECTIVE STUDY
}

\author{
Alexandra Eugenia Bastian ${ }^{1,2}$, Vlad Mageriu', Emilia Manole ${ }^{1,3}$ \\ ${ }^{1}$ Colentina University Hospital, Department of Pathology, \\ Colentina Research Center, Bucharest, Romania \\ ${ }^{2}$ University of Medicine and Pharmacy, Department of Pathology, Bucharest, Romania \\ 3 "Victor Babes" National Institute of Pathology, Molecular Biology Laboratory, \\ Bucharest, Romania
}

\begin{abstract}
Objectives. Congenital myopathies (CM) are a highly heterogeneous group of disorders with genetic cause, characterized by motor deficit and weakness usually manifesting in the neonatal period, with slowly progressive or non-progressive course and affecting both sexes. MC classification has undergone many changes over time, and in recent years molecular genetic studies have enabled identification of novel genes and mutations, thus increasing the diagnostic complexity. We wanted to study the incidence and morphological features of the CM cases diagnosed by muscle biopsy in the Pathology Department of Colentina University Hospital over a period of 10 years (09.2005- 09.2015).

Materials and methods. We retrospectively reviewed all the muscle biopsies diagnosed with different types of CM. Muscle biopsies were performed and specifically processed using routine and special stains on cryosections, semithin and ultrathin sections for ultrastructural examination. In all the cases we reassessed the clinical and laboratory data.

Results. From a number of 1,530 peripheral nerve and muscle biopsies performed and analyzed in the 10 years period we diagnosed $\mathrm{CM}$ in 15 cases, representing $1.03 \%$ of the total. Of these, five were "central core myopathies", five centronuclear/myotubular myopathies, one case of nemaline myopathy, one case of "reducing body myopathy" and three cases with congenital fiber type disproportion. Reassessment of morphological data in the clinical context allowed us to identify numerous overlaps between subtypes both in the clinical and pathological picture

Conclusions. The reduced number of MC identified in our country suggests that these diseases are probably underdiagnosed or diagnosed late, requiring a better understanding of the various clinical and pathological particularities. In the accurate diagnostic algorithm, muscle biopsy remains essential to establish the type of CM and thus to direct genetic tests.
\end{abstract}

Keywords: congenital myopathies, central cores, multiminicores, nemaline rods, centronuclear myopathy

\section{INTRODUCTION}

Congenital myopathies $(\mathrm{CM})$ are rare inherited primary disorders of musculature causing generalized weakness distributed more often proximal, presenting often in the neonatal period, hypotonia expressed in the clinical picture of floppy child and often delayed motor development in the first years of life, resulting in death due to cardiorespiratory complications. In other cases, the onset of clinical features is late during childhood or even in adulthood, and in such situations the life span may be close to normal. In most of the CM the inheritance is autosomal recessive or autosomal dominant, so both sexes are nearly equally affected. X-linked forms are also encountered and are manifested in affected boys and symptomatic female carriers. De novo mutations are common as well. Most of the forms are clinically stable, while others have a slowly progressive course. The morphological features of $\mathrm{CM}$ were described with the advance of histochemical, enzyme histochemical and ultrastructural 
techniques and further development of molecular genetics identified the etiology of many types of CM (Table 1). Many mutations in different genes encoding for muscular structural proteins were described in the last years and were associated with specific patterns of muscular abnormalities, but there are other CM with yet unknown genetic defects. Another important issue is, like in many other genetic muscle diseases, that genotype-phenotype correlations are complex: a specific subtype of CM is due to mutations in many genes, while a different muscular pathology may be associated with mutations in the same gene. Furthermore, even the underlying pathophysiological mechanisms are still debated (1-3).
The International Standard of Care Committee for Congenital Myopathies published in 2014 a consensus statement providing updated guidelines for the physicians involved in diagnosing CM (1). Based on these recommendations, we aimed to assess the relative incidence and spectrum of CM subtypes in the Romanian pediatric and adult population, based on the pathological aspects identified on the muscle biopsies of these patients. Even now, with increased application of next generation sequencing techniques, the subtypes of CM are still defined on the basis of characteristic histopathological features.

TABLE 1. The most important congenital myopathies, and their main pathological aspects

\begin{tabular}{|c|c|c|c|}
\hline Type of CM & Related genes & Inheritance & Pathological aspects \\
\hline Myotubular myopathy & MTM 1 (myotubularin) & X-linked & $\begin{array}{l}\text { - single central nucleus in } 4-40 \% \text { of the fibers } \\
\text { - reduced fiber size } \\
\text { - type I fiber predominance }\end{array}$ \\
\hline $\begin{array}{l}\text { Centronuclear } \\
\text { myopathy }\end{array}$ & $\begin{array}{l}\text { BIN } 1 \text { (amphiphysin) } \\
\text { DNM } 2 \text { (dynamin 2) } \\
\text { RYR } 1 \text { (ryanodine receptor } 1 \text { ) }\end{array}$ & $\begin{array}{l}A R \\
A D \\
A R\end{array}$ & - central nuclei in almost all the fibers \\
\hline Nemaline myopathy & $\begin{array}{l}\text { NEB (nebulin) } \\
\text { TPM } 3 \text { (alpha slow tropomyosin 3) } \\
\text { ACTA } 1 \text { (skeletal alpha actin) } \\
\text { TPM } 2 \text { (beta tropomyosin 2) } \\
\text { CFL } 2 \text { (muscle specific cofilin 2) } \\
\text { TNNT1 (slow troponin-T) } \\
\text { KBTBD } 13 \text { (kelch repeat and BTB } \\
\text { domain containing 13) }\end{array}$ & $\begin{array}{c}A R \\
A D+A R \\
A D+A R \\
A D \\
A R \\
A R \\
A R\end{array}$ & $\begin{array}{l}\text { - nemaline bodies (rods) } \\
\text { - best seen on Gomori Trichrome stain } \\
\text { - in the center and in the periphery of muscle fibers } \\
\text { - contain mainly alpha actinin } \\
\text { - also actin, myotilin, tropomyosin, nebulin }\end{array}$ \\
\hline Central core disease & RYR 1 (ryanodine receptor 1 ) & $A D+A R$ & $\begin{array}{l}\text { - presence of cores (areas of absent oxidative enzyme stain) } \\
\text { - mainly in type I fibers } \\
\text { - fiber typing indistinct / marked predominance of type I }\end{array}$ \\
\hline $\begin{array}{l}\text { Congenital fiber type } \\
\text { disproportion }\end{array}$ & $\begin{array}{l}\text { ACTA } 1 \text { (skeletal alpha actin) } \\
\text { RYR } 1 \text { (ryanodine receptor) } \\
\text { TPM } 3 \text { (alpha slow tropomyosin 3) } \\
\text { SEPN } 1 \text { (selenoprotein N1) } \\
\end{array}$ & $\begin{array}{c}A D \\
A R \\
A D+A R \\
A R\end{array}$ & $\begin{array}{l}\text { - smallness of type I fibers } \\
\text { - type I fibers more numerous than type II }\end{array}$ \\
\hline $\begin{array}{l}\text { Multi-minicore } \\
\text { disease }\end{array}$ & SEPN 1 (selenoprotein N1) & AR & $\begin{array}{l}\text { - multiple small cores in } 60-80 \% \text { of the fibers of both types } \\
\text { - reduced activity on oxidative enzyme stains }\end{array}$ \\
\hline $\begin{array}{l}\text { Multi-minicore } \\
\text { disease with external } \\
\text { ophtalmoplegia }\end{array}$ & RYR 1 (ryanodine receptor 1 ) & $A R$ & - multiple small cores \\
\hline $\begin{array}{l}\text { Reducing body } \\
\text { myopathy }\end{array}$ & FHL 1 (four and half LIM domain) & X-linked & $\begin{array}{l}\text { - presence of reducing bodies in the cytoplasm } \\
\text { - dark green on Gomori Trichrome, reducing nitro-blue } \\
\text { tetrazolium }\end{array}$ \\
\hline $\begin{array}{l}\text { Sarcotubular } \\
\text { myopathy }\end{array}$ & $\begin{array}{l}\text { TRM } 32 \text { (tripartite motif-containing } \\
\text { 32) }\end{array}$ & $A R$ & $\begin{array}{l}\text { - multiple small rounded vacuoles } \\
\text { - more in type } 2 \text { fibers than in type I } \\
\text { - sarcoplasmic reticulum membranes } \\
\text { - Z-disk streaming }\end{array}$ \\
\hline $\begin{array}{l}\text { Hyaline body } \\
\text { myopathy (myosin } \\
\text { storage myopathy) }\end{array}$ & $\begin{array}{l}\text { MYH } 7 \text { (cardiac beta myosin heavy } \\
\text { polypeptide 7) }\end{array}$ & $A D$ & $\begin{array}{l}\text { - hyaline subsarcolemmal eosinophilic bodies } \\
\text { - mostly in type I fibers } \\
\text { - lacking oxidative or glycogen activity, stain for myosin ATP ase } \\
\text { pH } 4.35\end{array}$ \\
\hline Cap myopathy & $\begin{array}{l}\text { ACTA } 1 \text { (skeletal alpha actin) } \\
\text { TPM } 2 \text { (beta tropomyosin 2) } \\
\text { TPM } 3 \text { (alpha slow tropomyosin 3) }\end{array}$ & $\begin{array}{l}A D \\
A D \\
A D\end{array}$ & $\begin{array}{l}\text { - caps located in the muscle fiber periphery } \\
\text { - stain dark on Gomori Trichrome } \\
\text { - mostly in type I muscle fibers that are small }\end{array}$ \\
\hline
\end{tabular}




\section{MATERIALS AND METHODS}

We retrospectively analysed the cases morphologically assessed over a ten years period at the Pathology Department of Colentina University Hospital in the laboratory for neuromuscular pathology. We selected and analyzed the muscle biopsies of all cases previously diagnosed as CM. The skeletal muscle biopsies were performed in our Department of Surgery under local anaesthesia, by a trained surgeon and the myopathologist, after informed consent was obtained from all patients or, in children, from their parents. The selection of the muscle to be biopsied was made by the neurologist/ pediatric neurologist after a detailed clinical examination, sometimes followed by imaging studies, in order to choose a moderately affected muscle, thus avoiding to take the biopsy from a severely involved muscle with end-stage pathology. The samples were oriented immediately after removal and fresh frozen in isopentane precooled in liquid nitrogen at $-160^{\circ} \mathrm{C}$ and stored at $-80^{\circ} \mathrm{C} .7 \mu \mathrm{m}$ thick serial muscle cryosections were subjected to routine and special stainings: haematoxylin-eosin (HE), modified Gomori trichrome, van Gieson (GT), Sudan Black B, Periodic acid Schiff (PAS), succinic dehydrogenase (SDH), lactic dehydrogenase (LDH), nicotinamide adenine dinucleotide tetrazolium reductase (NADH), cytochrome c oxidase (COX), adenosine triphosphatase - ATPase pre-incubated at $\mathrm{pH}$ 9.4, 4.63 and 4.35. Immunohistochemical stains for some muscle proteins had been performed also on cryosections in certain cases or for differential diagnosis. Another piece of muscle tissue had been preserved in glutaraldehyde and embedded in resine for further ultrastructural analysis, essential in CM cases. A part of the sample had been formalin fixed and embedded in paraffin for conventional histopathological processing and routine stainings. We retrieved all the clinical data, including family history, age at presentation, pattern of muscle weakness and disease progression, extramuscular signs, level of creatine phosphokinase (CK) and electromyogram findings.

\section{RESULTS}

In a period of ten years (September 2005 - September 2015), out of 1,530 patients reffered to us for muscle/muscle and sural nerve biopsy we diagnosed a total of fifteen cases of CM of different subtypes: central core disease, nemaline myopathy, centronuclear/myotubular myopathies, congenital fiber type disproportion and reducing body myopathy.

\section{Central core disease}

Among the analyzed cases we identified five cases of central core disease: one child and four adults. The morphological diagnosis was based on the presence of cores, defined as single or multiple extensive areas in most of the muscle fibres that are devoid of oxidative enzyme activity, centrally or peripherally located, caused by absence of mitochondria and sarcoplasmic reticulum in the core region (Fig. 1) (4). Cores were best highlighted on $\mathrm{SDH}, \mathrm{LDH}, \mathrm{NADH}$ and COX stains.

Another important aspect was type I fibre uniformity, which may occur even in the absence of cores. Fibrosis and adipose metaplasia were prominent features in cases with long history of symptoms, thus resembling a congenital muscular dystrophy, a diagnosis that had to be ruled out. One of the patients was a very hypotonic child aged 1 year and 4 monts, with the appearance of floppy child and life-threatening breathing problems from birth with respiratory failure. His left quadriceps muscle biopsy revealed the presence of diagnostic cores in more than $80 \%$ of the muscle fibers. Another case was a 25 years old man with fatigability noted first at the age of 10 years, atrophy of the distal musculature in the lower limbs, and difficulties in climbing stairs. The clinical suspicion was a form of limb-girdle muscular dystrophy. CK level was always in the normal limits and EMG was mildly myopathic. On the left deltoid muscle biopsy (Fig. 1) we identified a variation in the fiber size, almost only type I fibers on ATP-ase stains and numerous excentric cores and therefore diagnosed him with central core disease.

The genetic test subsequently performed in France confirmed our diagnosis and proved a de novo p.Arg4861His (c.14582G>A) mutation on RYR1 gene, which was not detected in his parents. The mutation was located in the transmembrane domain of the calcium channel.

\section{Nemaline myopathy}

Nemaline myopathy is characterised morphologically by the presence of nemaline bodies consisting of proteins derived from the $\mathrm{Z}$ disc and thin filament $(5,6)$. In the last ten years we only diagnosed one case of nemaline myopathy in a boy of 15 years with no family history of muscle diseases. He had muscle weakness and hypotonia since early childhood predominantly in facial muscles, facial dysmorphisms with long face, a tent shaped mouth, high arched palate, also weakness of cervical and trunk flexor, foot dorsiflexor and finger extensor 

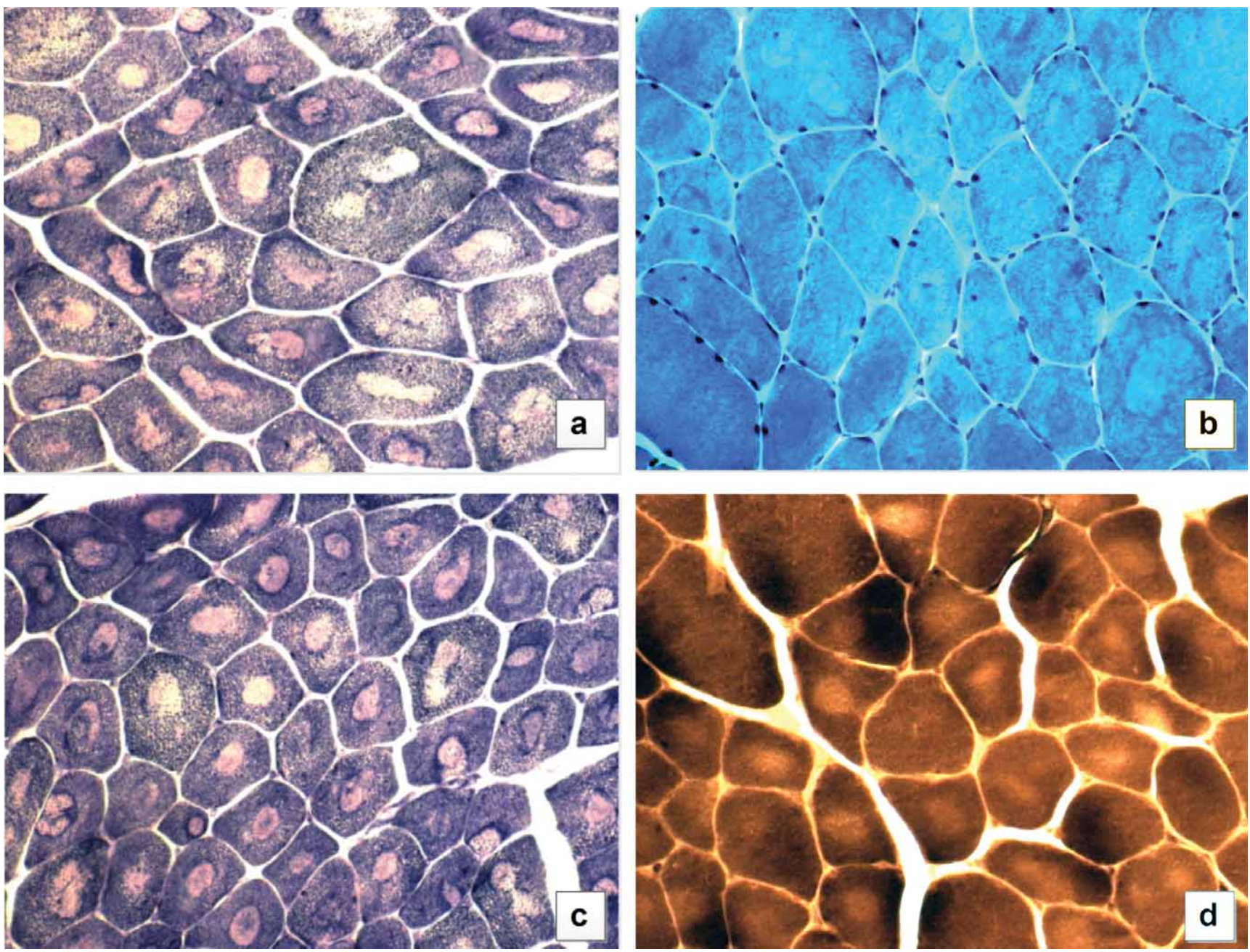

FIGURE 1. Central core disease: presence of cores on NADH staining (a,c), on modified Gomori Trichrome staining (b) and ATP-ase preincubated at pH 4.35 (d). (Original magnification, Ob. 40x)

muscles. Furthermore, the patient had respiratory insufficiency, dysphagia, foot deformities, scoliosis, chest deformities, superior and inferior limbs contracture and had a waddling gait. CK level was slightly elevated and EMG was myopathic. The pediatric neurologist made the clinical diagnosis of probable congenital myopathy, suspecting a nemaline myopathy on clinical signs and ordered a muscle biopsy from the right gastrocnemius, showing numerous subsarcolemmal and intermyofibrilar nemalinic rods, looking like dark red-blue structures identified on modified Gomori trichrome stain and uniformity of type I fibers. The rods could be identified in the cytoplasm but not also in the nuclei. The mean diameter of the muscle fiber was under the normal limits for the age and there was a severe increase in the interfascicular collagen. The presence of rods in over $50 \%$ of the muscle fibers made the pathological diagnosis of nemaline myopathy (Fig. 2a, b). Interesting is that the most of fibers looked similar to those seen in cap myopathy, especially on ATPase staining (Fig. 2c. One month after the biopsy, before any genetic confirmation could be obtained, the boy died of severe respiratory insufficiency and pneumonia.

\section{Reducing body myopathy}

There was only one patient in this group, a woman aged 25 years with late onset of symptoms. She had predominanly proximal assymetric scapuloperoneal weakness and scoliosis. CK level was three times the normal value and EMG revealed mixed neurogenic and myopathic changes. The biopsy performed in the right gastrocnemius muscle identified a marked variation in the fiber size, some necrotic fibers, increased number of internally located nuclei, splitting of fibers, small groups of atrophic fibers, but the most prominent morphological aspect was the presence of granular bodies located in the cytoplasm, often near the nucleus, looking dark-green on modified Gomori trichrome stain (Fig. 3). These aggregates reduce nitro-bluetetrazolium (NBT) and thus stain strongly with the 

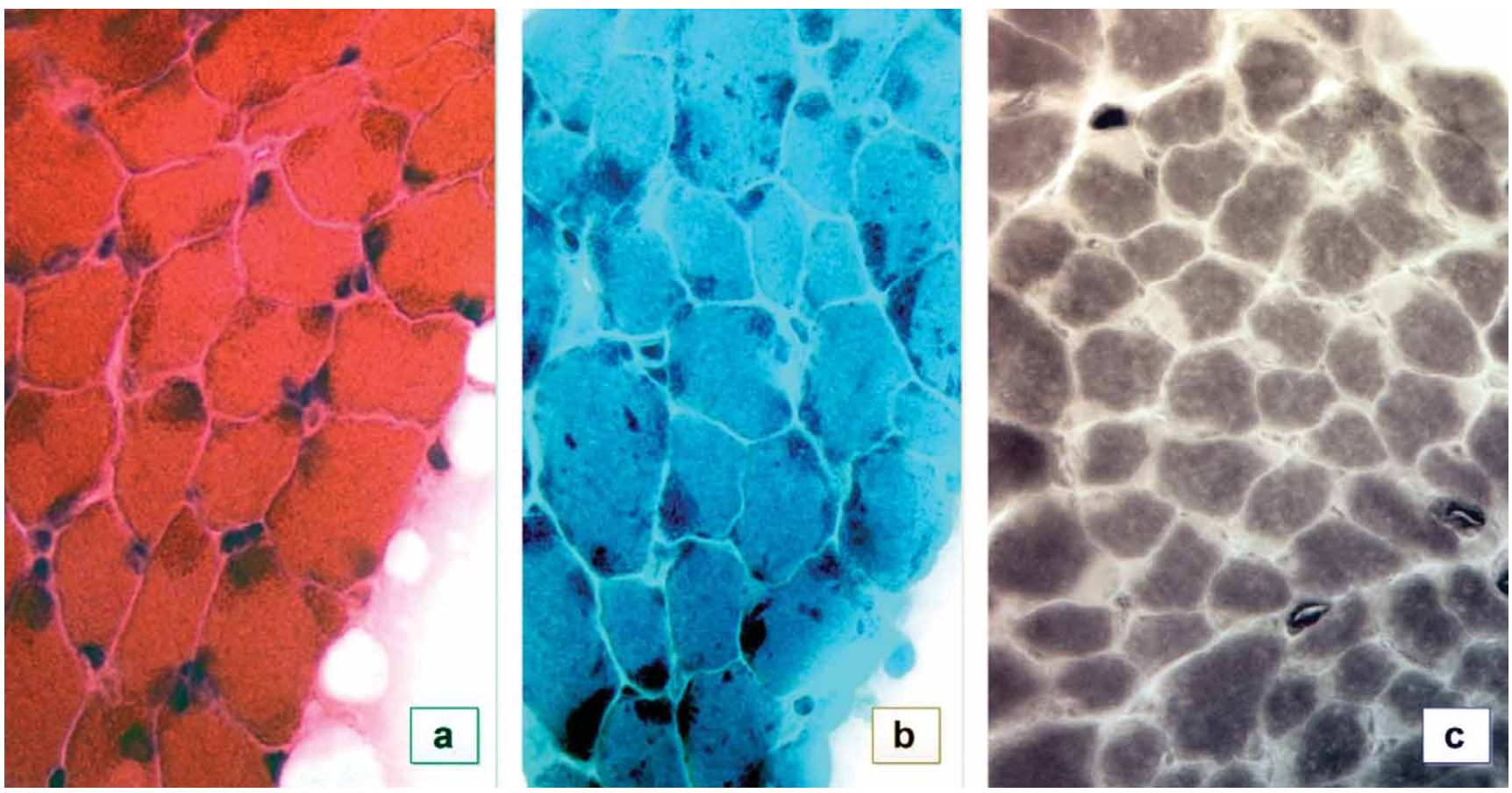

FIGURE 2. Nemaline myopathy: variation in the fiber size and rods on HE (a); modified Gomori Trichrome stain showing nemaline rods in the subsarcolemmal regions (b); a subsarcolemal pale stained "cap" is seen in almost all fibers on ATPase preincubated at pH 4.63 (c). (Original magnification Ob. 40x - panels a,b and 20x-panel c)
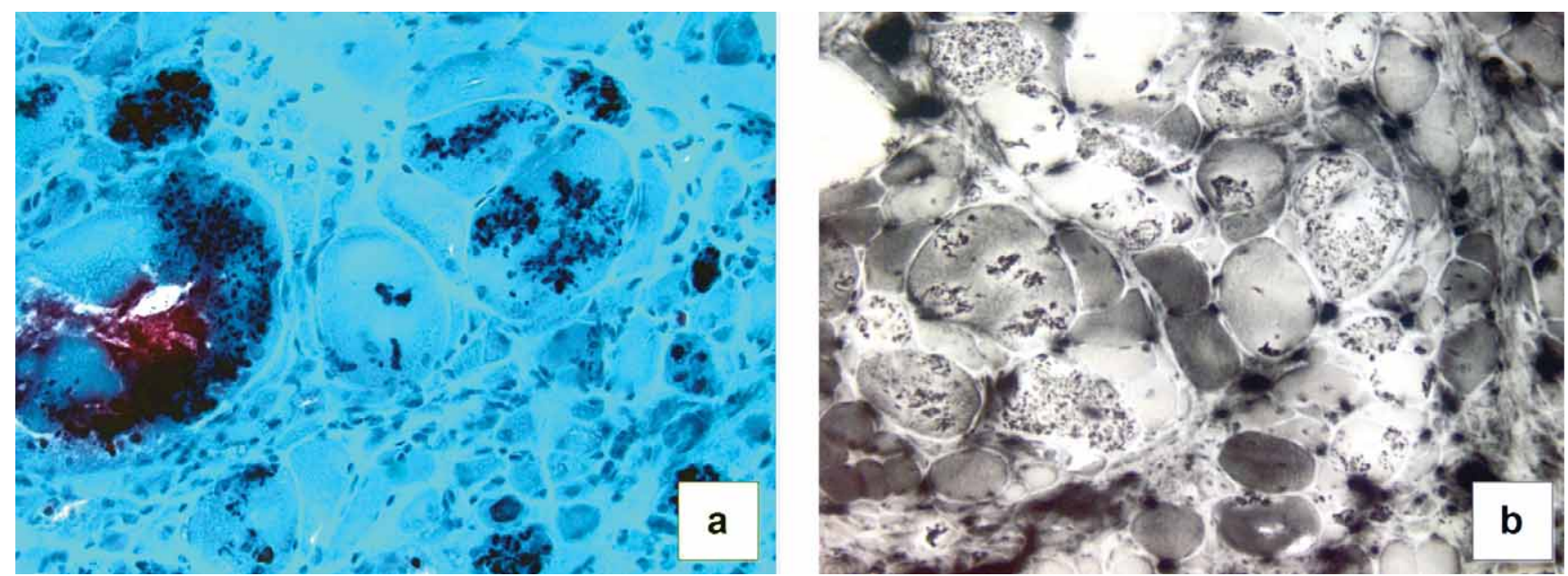

FIGURE 3. Reducing body myopathy: variation in the fiber size and reducing bodies in the cytoplasm, reactive for acid ATP-ases. Modified Gomori trichrome stain (a); ATP-ase pH 4.63 (b) (Original magnification Ob. 40x)

menadione-NBT stain, presumably because of their high content of sulfhydryl group (Fig. 3). Under the high suspicion of reducing body myopathy, the case has been sent to Prof. M. Fardeau (Institute of Myology in Paris) for second oppinion and electron microscopy. The typical electron-dense granular filamentous appearance of the aggregates confirmed our diagnosis.

\section{Centronuclear/myotubular myopathies}

We examined a total of five cases with a significant number of centrally located myonuclei, as the hallmark of centronuclear myopathies (7). In two pediatric cases aged 9 and 7 years the single central nuclei were prominent and occupyed a large volume of the fiber, highly suggesting centronuclear myopathy (Fig. 4). Other morphological features were reduced average fiber size and predominance of type I fibers that were smaller than type II fibers. The central areas of the fibers showed reduced myofibrillar ATPase reaction and decreased oxidative enzyme activity (Fig. 4). Another obvious features were myofibrils with radiating structure on oxidative enzyme stains looking like spokes of a wheel (Fig. 4). In both cases, the onset was in early childhood with severe hypotonia, proximal and dis- 

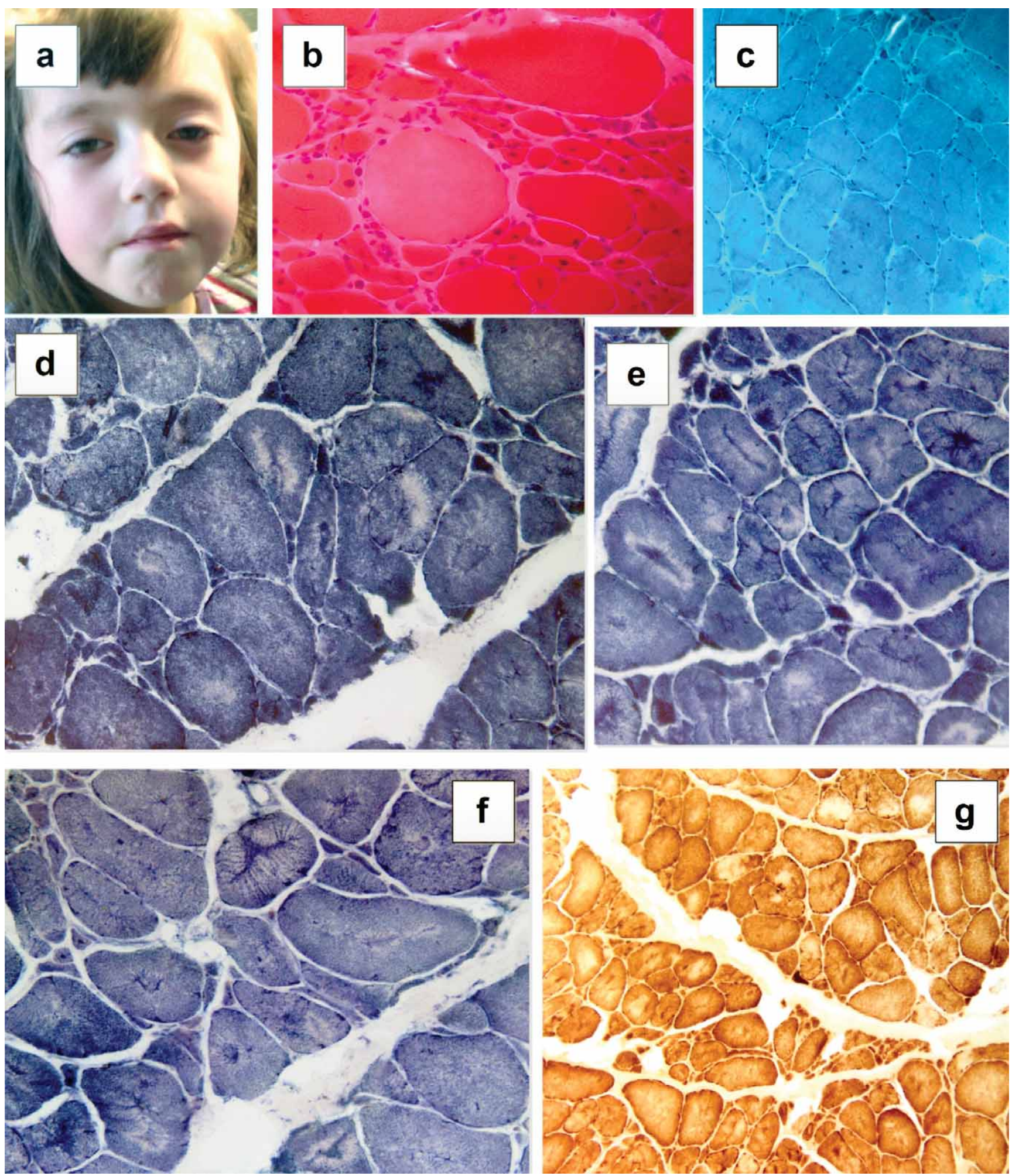

FIGURE 4. Centronuclear myopathies: characteristic facial weakness, long face and ptosis (a); biopsy with morphological aspects of centronuclear myopathy: centrally located myonuclei mostly in small fibers (b,c) (HE, GT); radial strands like spoke of wheel on NADH stain $(d, e)$ and $L D H$ stain $(f)$ in some fibers, and pale central areas devoid of mitochondria in other muscle fibers (Original magnification Ob. 40x), lacking cytochrome $C$ oxidase activity (COX stain, Original magnification Ob. 20x) (g)

tal simmetric nonprogressive weakness, ptosis and ophtalmoplegia, respiratory inssuficiency and craniofacial dysmorphism consisting in a long face, dolichocephalic skull and high arched palate. The pronounced facial weakness, particularly affecting the lower face and mouth resulted in the characteristic "myopathic facies" (Fig. 4a). CK levels were mildly elevated and EMG showed myopathic features. The other three case were adults and among them there was a man aged 46 years with the clini- 
cal suspicion of muscular dystrophy. He had moderate and very slowly progressive weakness since early childhood predominantly in the proximal musculature, he was always poor in sport and had difficulties walking and climbing stairs. CK levels were moderately elevated. His biopsy from the left deltoid muscle showed moderate variation in the fiber size and a large number of internal nuclei. On oxidative enzyme stains we noticed a large number of fibers with radiating strands of sarcoplasm from the central nucleus, but also other fibers with corelike structures. The semithin sections showed, besides muscle fibers with one or more central nuclei, many fibers with central cores structures, unstructured sarcomeric fibrillar aggregates areas with prominent $\mathrm{Z}$ bands material, clear zones without myofilaments, a central accumulation of abnormal mithocondria (Fig. 5, a-j). The other two cases were females aged 22 and 36 years and also presented with proximal weakness. In all of the adult cases we noticed increased number of internally placed nuclei, moderate fiber size variation and mild increase in endomysial connective tissue. Because of the large number of internal nuclei a differential diagnosis with myotonic dystrophy based on clinical signs and genetic tests is required in such cases.
FIGURE 5. Centronuclear myopathies: Semithin sections showing central nuclei, especially in small fibers (longitudinal sections - $a, b$; transversal sections $-c, d$ ); clusters of abnormal mitochondria and clear zones without myofilaments in center of some fibers $(e, f)$; core-like structures with myofibrillar disruption and focal loss of Z-bands (g) or Z-line streaming $(i, j)$; some fibers on transversal sections shows central areas with myofilaments disruption (c, h). (toluidine blue staining, Original magnification Ob. 40x oil immersion)

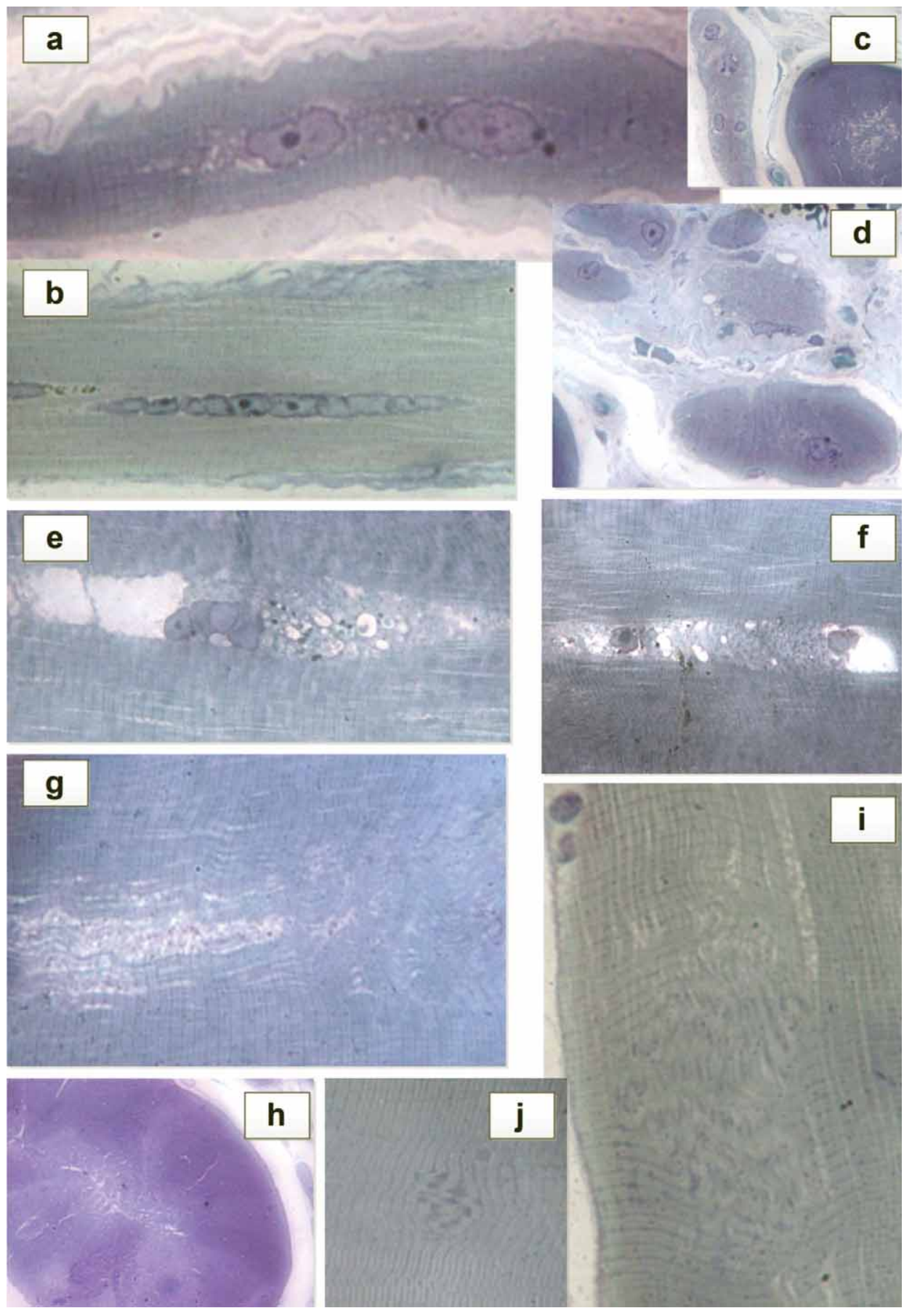




\section{Congenital fiber type disproportion}

During the study period we diagnosed three cases of congenital fiber type disproportion (CFTD), all of them in children, aged 1 year and 9 months, 3 years and 12 years. All of the patients were males. While the younger child was very hypotonic and had severe respiratory insufficiency, the other two only presented mild diffuse weakness, reduced tendon reflexes and scoliosis, highlighting the wide variation of symptoms in CFTD. CK levels were normal in all of the cases. The muscle biopsies showed in all the three cases the characteristic bimodal distribution of fiber sizes with type I fibers being more numerous and smaller than type II fibers with at least $12 \%$ as the only morphological abnormality (Fig. 6).

\section{DISCUSSIONS}

$\mathrm{CM}$ are clinically, genetically but also morphologically very heterogenous diseases. For most of the frequent forms and even for some of the rarer ones the causative gene defects were identified in the last years, revealing an interesting and complex spectrum. For each of the gene there is a wide phenotypic variation reflected in very different age of onset from birth, with neonates who are not able to survive, while in other cases the disease starts in childhood or even in late adulthood, so that in most of the CM there are three distinct clinical subtypes: a severe infantile form, a benign congenital one and adult onset form. Moreover, the diversity of clinical pictures is completed by large overlap of pathology in $\mathrm{CM}$, varying morphology being associated with
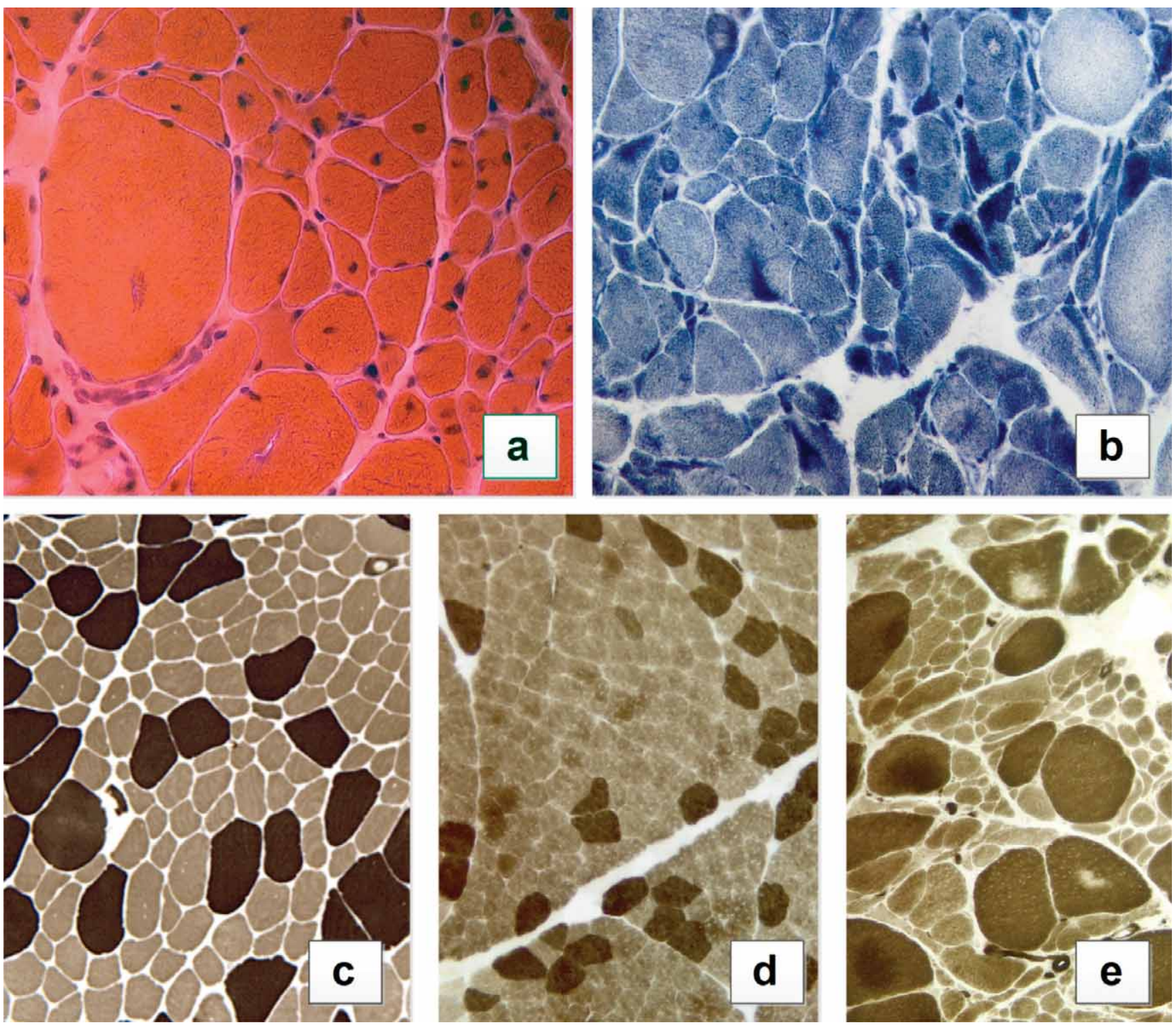

FIGURE 6. Congenital fiber type disproportion: important variation in the fiber size and some fibers with central nuclei $(H E-a)$, some fibers with central cores-like structures (NADH - b); predominance and hypotrophy of type I fibres (ATP-ase $\mathrm{pH}$ 9,4); type I fibers are dark and type II are light $(c, d, e)$; in panel e it can be noted two fibers with areactive central areas. 
defects in the same gene, while very similar pathology may be caused by defects in different genes (2). For these reasons, directing molecular analysis to reach a precise diagnosis requires a combination of clinical investigations and morphological assessment of frozen sections of muscle using routine, Gomori trichrome and oxidative enzyme stains and electronmicroscopy. Thus, is obvious that the muscle biopsy should be performed and analysed in specialised centres with facilities to work-up such cases. A piece of formalin-fixed muscle tissue later embedded in paraffin would certainly miss the diagnosis of CM.

In this study we were particularly interested in the pathological overlaps, more and more described in $\mathrm{CM}(8,9)$, because they may represent overlapping pathomechanisms. In all the analyzed cases we identified pronounced type I predominance or even uniformity of fiber types with type I hypotrophy. Another common morphological aspect is the increased number of internally located nuclei, and even the presence of a small number of muscle fibers with central core-like areas, not reactive on oxidative enzyme stains, suggesting lack of mitochondria COX activity. In our actual knowledge, cores and rods does not necessarily imply different clinical entities, but are part of a spectrum of morphological aspects $(10,11)$. In the adult case of centronuclear myopathy presented above, we found on the same biopsy myonuclei in the center of many fibers and cores in other fibers, once again underlining the pathological overlapping. This pathological pattern was found in CM in adult patients with a BIN1 mutation (12), the genetic analysis proving to be very imprtant for a more accurate diagnosis. The variability of pathology appears to be related to the sampled muscle, the age at biopsy and to the change of morphology in time. Another extremely important practical aspect is that core myopathies with mutation in the ryanodine receptor gene carry a very high risk of malignant hyperthermia in response to anesthetic triggering agents, so that a precise diagnosis in such cases will help preventing this life-threatening complication (13-17). Another overlapping aspect we should mention is that of the pacient with nemaline myopathy. Many fibers looked like those in „cap” myopathy, especially on APT-ase staining. Cap myopathy first described in 1981 by Fidzianska and co-workers (18), was shown to be produced by a mutation in b-tropomyosin (TPM2) gene in a patient (19). The diversity of clinical phenotypes in $\mathrm{CM}$ is very convincingly reflected in our studied cases. We diagnosed both young children with very severe weakness and re- spiratory insufficiency starting in the neonatal period, older children with milder symptoms but also adults with long history of their disease. A feature of our study is that we diagnosed many cases of $\mathrm{CM}$ in adulthood, suggesting that in our country $\mathrm{CM}$ are recognized late in the disease progression and are probably underdiagnosed.

The clinical differential diagnosis in CM is complex and include forms of congenital muscular dystrophies, congenital myotonic dystrophy, spinal muscular atrophy, congenital myasthenic syndromes, metabolic myopathies including Pompe disease, as well as Prader-Willi syndrome. Not surprisingly, some of these diagnosis were clinically suspected in our patients. Patterns of clinical findings very highly suggestive for $\mathrm{CM}$ are prominent facial weakness with or without ptosis, generalised hypotonic posture, hyporeflexia, weakness and dysfunction of the respiratory and bulbar muscles. We could find combinations of these symptoms in the clinical pictures of our patients.

We were also interested in comparing our retrospective study with others in terms of incidence of $\mathrm{CM}$ and of the different subtypes. We diagnozed $\mathrm{CM}$ in 15 cases, representing $1.03 \%$ of all the muscle biopsies performed in the time of our study and the most important types of CM were found in the Romanian population in the last 10 years. To compare, in the same period of time we examined 78 cases of Duchenne muscular dystrophy and 31 cases of Becker muscular dystrophy or intermediate Duchenne-Becker forms. Core myopathies and centronuclear myopathies had a equal frequency. In 2013 Maggi et al. published a study on 66 patients diagnosed with CM over a period of 5 years in the U.K, of which 54 had a muscle biopsy and concluded that core myopathies were the most common form of CM (20). Other studies from large countries like India indicated that 50 out of 3,420 muscle biopsies over a period of 12 years were diagnosed as CM, representing a percentage of $1.46 \%$. Among the subtypes, the most prevalent type were centronuclear myopathies (21). In the large study of Nonaka out of 446 cases diagnosed in 21 years (in Japanese population), nemaline myopathy was the leading form of $\mathrm{CM}$ and the author concluded that $\mathrm{CM}$ are relatively common among the childhood myopathies (22). Thaha et al. in a study on 40 patients published in 2011 reported that centronuclear myopathy was the commonest type of $\mathrm{CM}$, followed by congenital fiber type disproportion (23). Jain et al retrieved all the cases diagnosed during a period of 6 years, and reported that $1.12 \%$ of the muscle biopsies were diagnosed as CM and 
the most common of them was central core disease followed by nemaline rod myopathy and multimini core disease (24). Obviously, there are differences between populations in the overall incidence and among subtypes. However, the global incidence of CM and of individual forms is yet mostly unknown,emphasizing the need to continue and improve their detection and this goal will be achieved through the widespread introduction of molecular genetic techniques, particularly next generation sequencing $(25,26)$.

A precise diagnosis in $\mathrm{CM}$ is essential not only for prognostic purposes and early management of complications, but also for genetic counseling, in waiting for future specific genetic therapies. A key aspect is also the psychological impact of a clearly established diagnosis for the patient and his family.

\section{CONCLUSIONS}

The most common subtypes of CM: core myopathies, nemaline myopathy and centronuclear/ myotubular myopathy were all diagnosed in the Romanian population in the last 10 years. We diag- nosed children as well as adults, mild cases but also very severe ones. The unexpectedly high proportion of adult cases in our study suggests that in our country these diseases are often diagnosed late or even remain undiagnosed. Even now, in the molecular era, achieving a precise diagnosis requires correlations of the morphological aspects provided by the muscle biopsy using histological, histochemical and electron microscopy techniques with the clinical phenotype. The difficulties in the diagnostic algorithm is increased by the clinical, genetical and pathological overlaps and demand a multidisciplinary approach of the cases.

\section{Acknowledgement}

This paper is supported by the Sectoral Operational Programme Human Resources Development (SOP HRD), financed from the European Social Fund and by the Romanian Government under the contract number POSDRU/159/1.5/S/137390/

\section{Conflict of interest}

The authors declare no conflict of interest.

\section{REFERENCES}

1. North K.N., Wang C.H., Clarke N. et al., Approach to the diagnosis of congenital myopathies. Neuromuscul Disord.2014; 24(2):97-116.

2. Ravenscroft G., Laing N.G., Bönnemann C.G. Pathophysiological concepts in the congenital myopathies: blurring the boundaries, sharpening the focus. Brain 2015;138(Pt 2):246-68.

3. Nance J., Dowling J., Gibbs E. et al. Congenital myopathies: an update. Curr Neurol Neurosci Rep 2012. 12(2): 165-174

4. Romero N.B., Lehtokari V.L., Quijano-Roy S., et al. Core-rod myopathy caused by mutations in the nebulin gene. Neurology, 2009. 73:, pp. 1159-1161

5. Laing N.G., Wallgren-Pettersson C. 161 st ENMC International Workshop on nemaline myopathy and related disorders, Newcastle upon Tyne, 2008, Neuromuscul Disord, 19(2009): 300-305

6. Goebel H.H., Piirsoo A., Warlo I. et al. Infantile intranuclear rod myopathy, J Child Neurol 12 (1997), pp. 22-30

7. Romero N.B. Centronuclear myopathies: a widening concept Neuromuscul Disord, 20 (2010): 223-228

8. Jungbluth H., Sewry C.A., Muntoni F., What's new in neuromuscular disorders? The congenital myopathies, Eur J Paediatr Neurol, 2003; 7(1): 23-30

9. Sewry C.A., Jimenez-Mallebrera C., Muntoni F., Congenital myopathies, Curr Opin Neurol, 2008; 21(5): 569-575

10. Monnier N., Romero N.B., Lerale J. et al., An autosomal dominant congenital myopathy with cores and rods is associated with a neomutation in the RYR1 gene encoding the skeletal muscle ryanodine receptor Hum. Mol. Genet., 2000; 9 (18): 2599-2608

11. Davis M.R., Haan E., Jungbluth H. et al., Principal mutation hotspot for central core disease and related myopathies in the C-terminal transmembrane region of the RYR1 gene, Neuromusc Dis, 2003, 13(2): 151-157

12. Bohm J., Biancalana V., Malfatt E. et al., Adult-onset autosomal dominant centronuclear myopathy due to BIN1 mutations, Brain, 2014; awu272: 1-11

13. Robinson R., Carpenter D., Shaw J. Mutations in RYR1 in malignant hyperthermia and central core disease. Hum Mutat, 27(2006), 977-989

14. Brislin R.P., Theroux. Core myopathies and malignant hyperthermia susceptibility: a review. Paediatr Anaesth. 2013. 23(9): 834-41

15. Snoeck M., van Engelen B.G., Kusters B. et al. RYR 1-related myopathies: a wide spectrum of phenotypes throughout life. Eur $\mathrm{J}$ Neurol. 2015, 22(7): 1094-112

16. Kraeva N., Heytens L., Jungbluth H. et al. Compound RYR1 heterozygosity resulting in a complex phenotype of malignant hyperthermia susceptibility and a core myopathy. Neuromuscul Disord. 2015, 25(7): 567-76

17. Løseth S., Voermans N.C., Torbergsen T. et al., A novel late-onset axial myopathy associated with mutations in the skeletal muscle ryanodine receptor (RYR1) gene, J Neurol, 2013; 260(6): 1504-1510

18. Fidzianska A., Badurska B., Ryniewicz B., et al., "Cap disease": new congenital myopathy. Neurology 1981; 31:1113-20

19. Lehtokari V.-L., Ceuterick-de Groote C., de Jonghe P. et al., Cap disease caused by heterozygous deletion of the $b$-tropomyosin gene TPM2, Neuromusc Dis, 2007, 17:433-442

20. Maggi L., Scoto M., Cirak S. et al. Congenital myopathies - Clinical features and frequency of individual subtypes diagnosed over a 5-year period in the United Kingdom, Neuromuscular Disorders 2013, Volume 23, Issue 3, 195 - 205

21. Uppin M.S., Meena A.K., Sundaram C. et al. Spectrum of congenital myopathies: A single centre experience. Neurol India 2013; 61: 254-9.

22. Nonaka I. Clinical and pathologic aspects of congenital myopathies. Neurol J Southeast Asia. 2001; 6:99-106

23. Thaha F., Gayathri N., Nalini A. Congenital myopathies: Clinical and immunohistochemical study. Neurol India. 2011; 59:879-83

24. Jain D., Sharma C., Sarkar C. et al. Congenital myopathies: A clinicopathological study of 25 cases. Indian J Pathol Microbiol 2008; 51: $474-80$

25. Gilbreath H.R., Castro D., lannaccone S.T. Congenital myopathies and muscular dystrophies. Neurol Clin 2014 32(3): 689-703

26. Bertini E., Darras B.T. Congenital myopathies: Rebuilding the natural history, one gene at a time. Neurology. 2015. 84(1): 15-6 